\title{
HOW THE PERCEIVED MASCULINITYAND/OR FEMININITY OF SOFTWARE APPLICATIONS INFLUENCES STUDENTS' SOFTWARE PREFERENCES
}

\author{
NICHOLE PINKARD \\ University of Chicago
}

\begin{abstract}
Increasingly, technology skills are becoming central to academic and economic success. More and more technological tools are becoming a vehicle for teaching and learning and a vehicle for buying and selling goods. However, research continues to show that women lag behind men in PC-ownership regardless of social economic status (SES) or education level (Lenhart, 2003; McConnaughey \& Lader, 1998); girls take fewer computer science and computer design courses and consistently rate themselves significantly lower than boys in terms of computer skills (AAUW, 1998); men outnumber women 6 to 1 in computer science Ph.D. programs (AAUW, 2000; Furger, 1998); and girls and boys are more likely to perceive computers as a male domain (Clewell, 2002; Eastman \& Krendl, 1987). Due to our society's increasing dependence on technological skills, the continued existence of the technological gender and cultural gap is a problem that must be explored with vigor in order to ensure that the technological tools we use provide equitable ${ }^{1}$ access to and experiences for women and children of color.
\end{abstract}

\section{LITERATURE REVIEW}

Researchers have put forth explanations for why the gender differences outlined above exist. Explanations include unequal access (Hanor, 1998; Miller, Chaika, \&

\footnotetext{
${ }^{1}$ It is important to note the use of the word equitable rather than equal. The use of the term equitable will be examined in the discussion section.
} 
Groppe, 1996), lack of female role models (AAUW, 1998; Bunderson \& Christensen, 1995; Dyer, 2004), climate of higher education (Bunderson \& Christensen, 1995), lack of software targeting feminine interests (Hanor, 1998; Purple Moon, 1995), the persistence of stereotypical character roles in software programs (Knupfer, 1998; Miller et al., 1996), differences in computer experiences (Becker \& Sterling, 1987; Dyer, 2004) and the perception that technology is primarily a male domain (AAUW, 1998, 2000; Hawkins, 1987; Miller et al., 1996; Miura, 1987; Shashaani, 1994).

These explanations have served as the basis for interventions designed to close the gender gap. Unfortunately, while many interventions have been successful, the gender gap continues to exist. An examination of theories to explain the gender gap ${ }^{2}$ reveals that the majority of explanations focus on the influence of social factors, such as parents' computer use patterns. Consequently, a majority of the interventions aimed at reducing the gender gap are based on socially oriented solutions-for instance, all-girl classes and girls-only after school programs.

While I believe that social interventions have great value in addressing and closing the gender gap, I wish to raise the question of whether our reliance on social interventions alone is enough to close the technological gender gap. In particular, I question of the relationship between designers' design decisions and students' gendered perceptions and preferences. In this study I explore 1) whether girls and boys interpret software as being targeted specifically to girls, boys, or both; and 2) whether or not a causal relationship exists between girls and boys software preferences and the perceived masculinity and/or femininity of software. I hypothesize that the more children perceive that software is designed with their interests in mind, the more likely they are to prefer the software program. If the majority of software programs designed for kids are perceived as more masculine than feminine, then we need to examine in more detail the influence of software design factors on the gender divide. In this study, I explore this hypothesis by examining whether students' software preferences are driven by perceptions of software masculinity and/or femininity.

\section{THEORETICAL BACKGROUND}

\section{Explanation of Design Factors}

Design factors refer to the decisions designers and developers of software programs make when creating a piece of software. These decisions range from the choice of topic (i.e., a "shooter" video game or a Barbie product) to decisions regarding activity structure, appearance of characters, language, colors, and

\footnotetext{
${ }^{2}$ See http://www.educ.sfu.ca/gentech/bibliography.html for an excellent bibliography if issues related to gender and technology.
} 
voices. I argue that, while many of the design decisions (with the exception of choice of characters and topics) might not appear to impact gendered perceptions, their combined effect might lead one gender to prefer the program more than the other. I argue that the existing research literature speaks little about the influence of design decisions on gendered preferences and perceptions. This connection has not been understood, I argue, because of the limited number of researchers studying issues related to gender and technology who have an intimate knowledge of the software design process. Few gender and technology researchers have the toolkit to explore the relationship between design decisions and gendered perceptions and preferences. It is a paradox. One reason women and girls might not engage with technology at the same level as men and boys is that the actual products they use are gendered by design. Because few women possess the skills to both design technology products and study their use (how many women are actually involved in high level gaming industry decision making is unclear, but most estimates put the number at less than 20\%), the impact of design decisions is often unexplored. Because their impact is unexplored these design decisions are reproduced again and again in other programs, thereby potentially reinforcing and reaffirming the gender gap. I argue that the question of whether technology is "gendered-by-design" is not addressed when the influence of design factors in the enactment of girl-only interventions is ignored. "Gendered" design decisions can be reinforced resulting in interventions that are socially, but not technologically, engaging - potentially leading to the reinforcement of perceptions with girls participating in the intervention, and within the larger society, that gender differences are immutable.

\section{Relationship between Subjects' Cultural Backgrounds and Social Factors}

A review of the gender and technology literature finds that few studies report the ethnicity and social economic status (SES) of subjects. If non-white subjects are included in the subject pool, rarely are results disaggregated based upon ethnicity, race, and/or SES. The heterogeneous nature of the subject pool raises the legitimate question of whether the social factors put forth as explanations for the gender divide are universal or are only relevant for the population of students included in the studies. In addition, the question is raised whether social factors, such as family computer use, are pushed forward because of their over sampling in a heterogeneous subject pool. I hypothesize that, by confining most studies of gender differences to middle and high SES Caucasian students from two parent households with access to computers in the home, the influence of social factors (e.g., parents' computing habits) on gender-specific technology perceptions has been over-emphasized at the expense of other potentially influential social factors (e.g., ethnicity, SES, teacher perceptions) and design factors (e.g., choice of activities, use of metaphors and characters). 


\section{Relationship between Design, Engagement, and Gender}

A number of studies have shown that significant differences exist in the ways girls and boys use and perceive technology. These differences are especially evident throughout high school and into young adulthood (AAUW, 1998; Becker \& Sterling, 1987; Honey et al., 1991; Schofield, 1995; Shashaani, 1994). However, our knowledge of how designers' design decisions affect student engagement is limited. Our knowledge of the relationship between design decisions and student motivation to use a program is based on research conducted by Malone and Lepper (1987) and Lepper and Malone (1987). In their studies components of a software program were turned on and off to isolate which design features enhanced students' engagement. Malone and Lepper explored the relationships between design factors and gender perceptions, however this exploration was secondary to question. Thus their results hint at a relationship between design features and gendered perceptions, but do not explicate the relationship.

My previous research (Pinkard, 1999, 2000, 2001a) attempted to build upon Malone and Lepper's findings by examining whether explicitly designing a computer-based learning environments ... Say, Say Oh Playmate ... based upon the cultural backgrounds of a specific targeted audience . . . African American girls ... would impact the motivation of students (both within and outside the target audience) to use a computer based learning environment and their learning experiences within that environment. Say, Say Oh Playmate uses animated African-American female characters to teach singing and clapping routines commonly heard in local playgrounds as a means of developing literacy skills. As expected, I observed that African-American girls showed stronger interest in using Say, Say Oh Playmate as exhibited by an examination of student software selections, use observations, and student/teacher interviews. An examination of the learning outcomes of all students using Say, Say Oh Playmate revealed no learning differences between targeted and non-targeted audience members. Both girls and boys improved beginning reading skills through the use of Say, Say, Oh Playmate (Pinkard, 2001b). These studies revealed that explicitly targeting the interests of girls through software design may help in bridging the current gender gap in computer usage. However, while these findings show a relationship between design and student engagement, these results can be expected because the software was designed explicitly to appeal to girls. In this study, I explore whether students have gendered perceptions regarding a range of commercial software programs not explicitly designed.

\section{Methods}

To date, most gender and technology studies have focused on adolescent, mid-to-high SES, Caucasian students with access to technology at home. In 
this study I explore gender differences among low-income African-American elementary students with limited access to computers outside of school. I hypothesize that, by bringing the voices and experiences of African-American students into this conversation, I can extend the research on the influence of social and design factors on students' computer skills, software perceptions and software preferences. The first influence that audience had was on the expanding of our definition of technology to include video game usage. This decision was made because of the disparity in African-Americans' computer versus video game ownership. To adequately understand the influence of home uses of technology, I had to extend our view technology to include video games as our interactions with the students revealed video games to be more prevalent in the home than computers.

\section{Participants}

The study site was a Detroit K-8 school with a population that is $99 \%$ African American. Most of the students live in nearby public housing, $82 \%$ qualify for free or reduced lunch programs and $79 \%$ live in families headed by single females. No data was available on the students' interactions with male family members not living within the immediate household. Data for this study was collected from one second grade and one fourth grade classroom and was based on an existing collaboration between myself and the two teachers. The different teaching styles that were observed in these classrooms provided another factor for exploring gender differences in technology use.

The second grade class contained 23 students (11 girls, 12 boys) who had the opportunity almost daily to work at the classroom's five computer workstations. In addition, each week the students were given a journal assignment requiring the use of a computer. A smaller number of students were given extra computer time to work on specific reading and math skills. As part of a separate four-month study on software choice, these students had access to Say, Say Oh Playmate and other programs during a 45-minute computer lab session scheduled once per week. For the most part, computer lab activities were not connected to classroom instruction.

The fourth grade class contained 18 students (11 girls, 7 boys) and two computers with two additional shared computers available if the teacher scheduled time in advance. In the fourth grade class students were cycled through computer activities twice weekly with most assignments tied to classroom instruction. Every Friday students were given 20 minutes each of free computer time. The students also had weekly scheduled 45-minute computer lab sessions during which they could choose from a variety of software programs, including Say, Say Oh Playmate. Computers were not given the same prominence in the fourth grade classroom that they were in the second grade classroom. 


\section{Technological Infrastructure}

Technology resources were shared throughout the school. Machines were stored on carts that enabled teachers to move computers between classrooms. The school had a computer checkout policy that required teachers to check machines out. Depending on the demand for machines, teachers might keep a machine for one class period of an entire day. All machines were stored in a room overnight for security. In addition to the machines on the cart, the school had a computer lab run by a computer teacher. The second and fourth grade classes participating in this study were considered exceptions to this process as they had access to four machines every day. All classrooms had one hour of computer lab time per week. However, the time in the computer lab was often unrelated to classroom activities.

While the school had a sufficient technological infrastructure, the school lacked software resources. A colleague and I collaborated with a committee of teachers to develop the technological capacity (Fishman \& Pinkard, 2001) of the staff. In addition to running technology training sessions, I worked with a committee of elementary teachers to select, purchase and load software programs to complement the school's curriculum. In addition to the commercial programs purchased, I field-tested two software programs I developed-Rappin' Reader ${ }^{3}$ and Say, Say Oh Playmate - as part of a study on the role of culturally responsive computer-based learning environments in improving literacy skills (Pinkard, 1999, 2000, 2001).

\section{Data Collection}

Data was collected via surveys designed to measure the students:

1. Attitudes toward computers

2. Use of computers and video games at home

3. Self-image concerning their ability to use computers

4. Perceptions of gender stereotypes regarding computer use and software programs

5. Personal preferences regarding software programs

To ensure that I was asking questions about software programs students had used, I only used programs that students had used while in school as determined by analysis of computer log files, teacher lesson plans, and field notes. However, I made an exception by including the general category of video games due to the high occurrence of video games in most students' homes.

Given the young ages and low literacy skills of the respondents, the researchers included icons representing the software programs on the survey form. The icons

\footnotetext{
${ }^{3}$ Rappin' Reader engages students in re-constructing the lyrics to popular rap songs by situating the task within simulated world of a recording studio.
} 
were taken from the application folder on the computer from which the students selected programs they wanted to use. Surveys were administered individually to second grade students. The fourth grade teacher administered the survey to her students by reading the survey questions aloud and pausing to allow her students to respond to each item. Questions were presented to second grade students in a mixed order to control for bias based on order of presentation. Three items were included to assess student perceptions regarding Say, Say Oh Playmate. The survey results were compiled and analyzed using SPSS statistical software package. Descriptive statistics, $t$-tests, chi-squares, one- and two-way ANOVAs, and Pearson's correlations were computed and reported below.

\section{Results}

Significance was set to $p<.05$ however, due to the small sample size results will be reported to the .1 level. Independent $t$-tests were conducted on students' answers to questions designed to ascertain their attitudes toward computers, access to and use of computers and video games outside of school, self-image concerning their ability to use computers and their overall perceptions regarding the abilities of boys and girls to use computers. To explore the question, "At what age, if any, do gender differences begin to appear?" surveys were analyzed to ascertain patterns among and across gender groups and grades. $T$-tests were conducted to analyze differences across and within grade and gender. No significant differences were found in the overall mean scores of second and fourth graders. However, significant differences were found for $t$-tests of independent means run to ascertain differences between genders within the same grade and across grades. Significant differences were also found for the same gender across grades.

\section{Technology Access and Ability Perceptions}

All students were asked, "Do you like using computers?" Students were given a 5-point Likert scale with values:

$$
\begin{aligned}
& 1=\text { Not at all } \\
& 2=\text { A little } \\
& 3=\text { It's okay } \\
& 4=\text { Most of the time } \\
& 5=\text { All of the time }
\end{aligned}
$$

For the most part, both boys and girls like using the computer. The means were 2B (4.83), 2G (4.82), 4G (4.81), 4B (4.14). ${ }^{4}$ However, the second grade boys'

\footnotetext{
${ }^{4}$ Throughout the rest of the article, $2 \mathrm{~B}=2 \mathrm{nd}$ grade boys, $2 \mathrm{G}=2 \mathrm{nd}$ grade girls, $4 \mathrm{G}=4$ th grade girls, $4 \mathrm{~B}=4$ th grade boys, $\mathrm{G}=2$ nd and 4 th grade girls, $\mathrm{B}=2 \mathrm{nd}$ and 4 th grade boys .
} 
mean score was significantly higher than the fourth grade boys' score. This difference was significant, $t(18)=2.12, p=.049$.

Table 1 depicts the mean scores for answers to the question "How many hours do you use the computer outside of school?" where:

$$
\begin{aligned}
& 1=\text { Never } \\
& 2=\text { A Little }(1 \mathrm{hr} / \mathrm{w}) \\
& 3=\text { Sometimes }(3 \mathrm{hrs} / \mathrm{wk}) \\
& 4=\text { Pretty much }(5 \mathrm{hrs} / \mathrm{wk}) \\
& 5=\mathrm{A} \operatorname{lot}(5+\mathrm{hrs} / \mathrm{wk})
\end{aligned}
$$

The low mean score reveals the cultural realities of the gap in computer access. Only seven second grade students and six fourth grade students reported using a computer outside of school. When asked where they have access to a computer, students more often than not reported access at places outside the home such as the library or a relative's home. Thus, even students with access have limited access.

During the design of the survey, I realized that home computer access only partly tells the story of African American, low SES student technology experiences and perceptions upon entering school. Familiarity with the AfricanAmerican community led us to explore the video game access and use patterns of the students. While low SES African-American students are not likely to have computers, they are likely to have access to video games in the home. Survey results revealed that of the 23 second grade students surveyed, 18 students reported playing video games at home-11 boys (91\%) and 7 girls $(59 \%)$. Fifteen of the 18 fourth grade students reported playing video games at home ( 5 boys, 10 girls). Table 1 depicts the mean score for answers to the question "How many hours do you play video games?" where I used the same Likert scale as the question "How many hours do you use the computer outside of school?" Comparison of mean score differences between computers hours versus video game hours shows, as expected, that there were significant differences favoring video game usage.

Table 1. Mean Computer Use vs. Mean Video Game Use

\begin{tabular}{lccc}
\hline Student group & $\begin{array}{c}\text { Mean weekly } \\
\text { computer use }\end{array}$ & $\begin{array}{c}\text { Mean weekly } \\
\text { video game use }\end{array}$ & $\begin{array}{l}\text { Sig. } \\
\text { diff. }\end{array}$ \\
\hline 2nd grade girl & 2.09 & 3.18 & \\
2nd grade boy & 2.6 & 3.75 & $p=.067$ \\
4th grade girl & 2.9 & 3.36 & \\
4th grade boy & 1.7 & 3.14 & $p=.082$ \\
\hline
\end{tabular}




\section{"Who Do You Think is Better at Using the Computer?"}

All students were asked "Who do you think is better at using the computer?" Students were given a 3-point rating scale:

$$
\begin{aligned}
& 1=\text { Girls are better } \\
& 2=\text { Boys and Girls are the same } \\
& 3=\text { Boys are better }
\end{aligned}
$$

Second and fourth grade boys and girls responded to this question and their ratings were compared using a four category, one-way ANOVA test. Table 2 reveals that category means ranked low to high were: second grade girls, fourth grade girls, second grade boys, and fourth grade boys $(M=1.36,1.82,2.3$, and 2.4, respectively). The overall test was significant, $F(3,37)=10.05, p=.001$. A $t$-test of the difference between the mean scores of girls (1.59) and boys (2.31) was significant, $t(39)=-4.709, p=.000$. The above significant mean differences confirm that girls were more apt to believe "girls are better" or "girls and boys are the same," while boys were more apt to believe "boys are better" or "girls and boys are the same." Neither group believed the opposite sex was better at using the computer.

To test whether the difference in means scores within gender observed in the ANOVA were significant, I conducted $t$-tests on means within gender. I found no significant difference in the answers between second and fourth grade boys, but significant differences between second and fourth grade girls. Second grade girls as compared to the fourth grade girls $(M=1.36$ versus $M=1.82)$ had a mean rating significantly favoring the perceived computer ability of girls. This difference was significant, $t(20)=2.33, p=.03$. Thus second grade girls more adamantly stated "girls are better" while the fourth grade girls were more likely to state "girls and boys are the same."

A related question asked students, "Do you think you are good at using computers?" using a a 5-point Likert scale. Mean scores are shown in Table 2. While the second grade girls believed most adamantly that girls were better at

Table 2. Comparison of General Perceptions of Computer Ability vs. Self-Report of Computer Ability

\begin{tabular}{lcc}
\hline Student group & $\begin{array}{c}\text { Who's better } \\
(1=\mathrm{G}, 2=\mathrm{S}, 3=\mathrm{B})\end{array}$ & $\begin{array}{c}\text { Computer ability } \\
\text { self-confidence }\end{array}$ \\
\hline 2nd grade girl & 1.36 & 4.00 \\
2nd grade boy & 2.3 & 4.25 \\
4th grade girl & 1.82 & 4.36 \\
4th grade boy & 2.4 & 4.00 \\
\hline
\end{tabular}


computers, their mean score ranking about their own computer ability, although not significantly different than the other groups, was tied with fourth grade boys at 4.0. The mean score for second grade boys was 4.25 and 4.36 for fourth grade girls. One might expect that the second grade girls would be more likely to rank themselves as good at using computers than the other groups of students given their view that girls are better than boys at using computers.

A positive correlation exists between the responses for the two questions "How many hours do you use the computer at home each week?" and "Do you think you are good at using computers?" $r(39)=.38, p=.01$. While not statistically significant, a correlation exists between the amount of time spent playing video games and students' self-confidence about using computers $(r=.308)$. As expected, an even stronger relationship exists between stated enjoyment of using computers and self-confidence in using them $(r=.407)$. The data show that the relationship between liking computers and self-confidence in using them is much stronger and statistically significant for second grade boys $(r=.612)$ than for second grade girls $(r=191)$. A weaker correlation was found for girls $(r=.055)$ than for boys $(r=.464)$ between the amount of time spent using video games in the home and self-confidence in the ability to use a computer.

\section{Second Grade Students' Perceptions of Say, Say Oh Playmate}

A secondary goal of this research was to analyze the perceptions of both girls and boys of Say, Say Oh Playmate, a program specifically targeted at girls. As stated earlier, students were participating in a study to ascertain the impact of Say, Say Oh Playmate on developing beginning literacy skills. The designer's specific target audience survey questions were included to gather information regarding students' gendered perceptions of Say, Say Oh Playmate. Specifically, the use of an explicitly "gendered" by design software program would provide insight into the relationship between perceptions, preferences, and design factors.

$T$-tests show that second grade girls liked Say, Say Oh Playmate much more than boys (respective means of 4.91 and 3.33, significant at $p=.0018$ ). In addition, girls reported feeling much more self-confident than boys in using the program, with a mean response score of 4.64 compared to a mean for boys of 3.58 to the question of how good they were at using Say, Say Oh Playmate (significant at $p=.0488$ ). Data showed a connection between girls feeling good about using the program and their self-perceptions about their overall ability to use a computer. Girls who like Say, Say Oh Playmate reported feeling very good about their ability to use the program $(r=.946, p<.01)$ and feeling very good about their ability to use computers in general $(r=.606)$.

At the same time, correlation data revealed a slightly negative relationship for the second grade girls between liking Say, Say Oh Playmate and 1) their interest in computers $(r=-.149), 2)$ the amount of time spent using computers $(r=-.567$, 
$p<.05)$, and 3$)$ the amount of time spent using video games $(r=-.148)$. A more substantial negative relationship was noted for the same girls between selfconfidence in using Say, Say Oh Playmate and the amount of time spent using computers $(r=-.740, p<.01)$. Positive correlations were noted between feeling self-confident about the ability to use Say, Say Oh Playmate and self-confidence in the ability to use computers in general $-r=.494$ for girls and $r=.266$ for boys.

\section{Software Preferences}

As stated, a goal of this study is to ascertain the relationship between software preferences and gender perceptions. To ascertain software preferences, I asked all students to identify and rank their five favorite software programs from a list of 12 programs that were used throughout the school year. Some programs varied from second to fourth grade due to the different learning needs of students. Students were asked to select their five favorite software programs, with first place votes receiving 5 points, second place votes receiving 4 , and so on down to fifth place votes receiving 1 point each. Given the limited number of students, I created a new variable "Top 3" during data analysis which counts the number of first, second or third favorite program votes a software program received. Table 3 presents students' software preferences by percentages and Table 4 depicts favorite programs sorted by grade and gender. Results show that two items appeared in the top-five list for both boys and girls-Arthur's Reading Race - and video games in general. However, disparities were found between second grade boys and girls in terms of the three remaining top-five favorites. The second grade boys' favorite program was ranked seventh by the second grade girls and the second girls' second and third favorite programs were ranked eighth and eleventh by the second grade boys.

\section{Preference Differences across Grades}

Half of the fourth grade $(50.0 \%)$ as compared to none of the second grade children rated Claris Works for Kids as one of their top three favorites. The chi-square test was significant, $\chi^{2}(1, N=41)=14.74, p<.001$. Fifty-seven percent of the fourth grade children as compared to $29 \%$ of the second grade children rated Mighty Math Number Heroes in their top three. The chi-square test was significant $\chi^{2}(1, N=41)=15.075, p=.002$. For the rest of the software programs there were no significant differences in software preferences when grade is the dependent variable.

\section{Preference Differences between Genders and across Grades}

When comparing favorite rankings between gender groups, the following findings were significant. Only $10 \%$ of boys rank Say, Say Oh Playmate in their top three compared to $64 \%$ of girls. The chi-square test was significant, $\chi^{2}(1$, 
Table 3. Student Software Preferences

\begin{tabular}{lrcccc}
\hline & \multicolumn{2}{c}{ 2nd grade } & & \multicolumn{2}{c}{ 4th grade } \\
\cline { 2 - 3 } \cline { 5 - 6 } Software title & Girls (\%) & Boys (\%) & & Girls (\%) & Boys (\%) \\
\hline Arthur's Reading Race & 100 & 17 & & NA & NA \\
Bailey's Book House & 18 & 0 & & NA & NA \\
Barbie Software & 55 & 0 & & 73 & 0 \\
Claris Works for Kids & 0 & 0 & & 26 & 17 \\
Grandma \& Me & 0 & 8 & & NA & NA \\
The Graph Club & 0 & & & 0 & 15 \\
Mighty Math Number Heroes & 0 & 58 & & 7 & 57 \\
Neighborhood Map Machine & NA & NA & & 67 & 43 \\
Rappin' Reader & 17 & 66 & & NA & NA \\
Say, Say Oh Playmate & 54 & 8 & & 64 & 14 \\
Video Games & 45 & 58 & & 44 & 86 \\
Smelly Mystery & 18 & 75 & & NA & NA \\
Storybook Weaver & NA & NA & & 0 \\
Table Top Junior & 0 & 8 & & NA & NA \\
\hline
\end{tabular}

$N=41)=13.3, p=.013$. Similar findings existed for Barbie Software. Sixty-three percent of girls ranked Barbie Software in their top three compared to none of the boys, $\chi^{2}(1, N=41)=18.36, p<.001$.

While I might expect to see the above differences due to the explicit nature of the targeted audiences for both Barbie Software and Say, Say Oh Playmate, differences were also found between genders within grades for programs not traditionally viewed as designed for a particular audience.

\section{Preference Differences between Genders within Grade}

A chi-square test reveals that second grade girls unanimously ranked Arthur's Reading Race in their top three, while only $17 \%$ of all boys ranked it in their top three, $\chi^{2}(1, N=23)=4.439, p=.03$. Seventy-five percent of second grade boys ranked Smelly Mystery in their top three compared to only $18 \%$ of second grade girls. Again, this difference was significant $\chi^{2}(1, N=23)=7.425, p=.006$. Fifty-eight percent of second grade boys ranked Mighty Math Number Heroes in their top three compared to none of the second grade girls, $t(23)=-3.75, p=.01$. Sixty-six percent of second grade boys ranked Rappin' Reader as their favorite program compared to $17 \%$ of second grade girls, $t(23)=-3.33, p=.02$. 
Table 4. Favorite Program Rankings

\begin{tabular}{lllll}
\hline Ranking & \multicolumn{1}{c}{$\begin{array}{c}\text { 2nd grade } \\
\text { girls }\end{array}$} & \multicolumn{1}{c}{$\begin{array}{c}\text { 2nd grade } \\
\text { boys }\end{array}$} & $\begin{array}{c}\text { 4th grade } \\
\text { girls }\end{array}$ & $\begin{array}{c}\text { 4th grade } \\
\text { boys }\end{array}$ \\
\hline 1st & $\begin{array}{l}\text { Arthur's Reading } \\
\text { Race }\end{array}$ & Smelly Mystery & Barbie Software & Video Games \\
2nd & Barbie Software & Rappin' Reader & $\begin{array}{l}\text { Neighborhood } \\
\text { Map Machine }\end{array}$ & $\begin{array}{l}\text { Mighty Math } \\
\text { Number Heroes }\end{array}$ \\
3rd & $\begin{array}{l}\text { Say, Say Oh } \\
\text { Playmate }\end{array}$ & $\begin{array}{l}\text { Mighty Math } \\
\text { Number Heroes (tie) }\end{array}$ & $\begin{array}{l}\text { Say, Say Oh } \\
\text { Playmate }\end{array}$ & $\begin{array}{l}\text { Neighborhood } \\
\text { Map Machine }\end{array}$ \\
4th & Video Games & Video Games (tie) & - & - \\
\hline 5th & $\begin{array}{l}\text { Bailey's Book } \\
\text { House }\end{array}$ & $\begin{array}{l}\text { Arthur's Reading } \\
\text { Race }\end{array}$ & - & - \\
\hline
\end{tabular}

\section{Perceived Software Masculinity and Femininity}

I hypothesize that students perceive software as designed for someone. The question I am exploring is whether students perceive software as designed for them. To ascertain their perceptions, students were asked "Who do you think would like this computer program better?" for each software program included in the study. Students were given three options: 1) girls, 2) both, or 3) boys. Data on student perceptions of their favorite software programs' targeted audiences by gender are presented as Figure 1.

\section{Second Grade}

The data show that second grade girls only viewed two programs as overwhelmingly designed for them-Barbie and Say, Say Oh Playmate, two programs as designed for girls and designed for both-Bailey's Book House and Claris Works for Kids. Four programs as designed for both-Grandma and Me, The Graph Club, Video Games, Arthur's Reading Race, and Table Top Jr. and three programs as designed for boys and designed for both-Rappin' Reader, Smelly Mystery and Mighty Math Number Heroes. Fourth grade boys viewed two programs as designed for girls Barbie and Say, Say Oh Playmate, five programs as designed for both-Grandma and Me, The Graph Club, Arthur's Reading Race, Smelly Mystery, and Table Top Jr., three programs designed for both and designed for boys-Book House, Claris Works for Kids, and Mighty Math Number Heroes and two programs as designed for boys-Video Games and Rappin' Reader. 


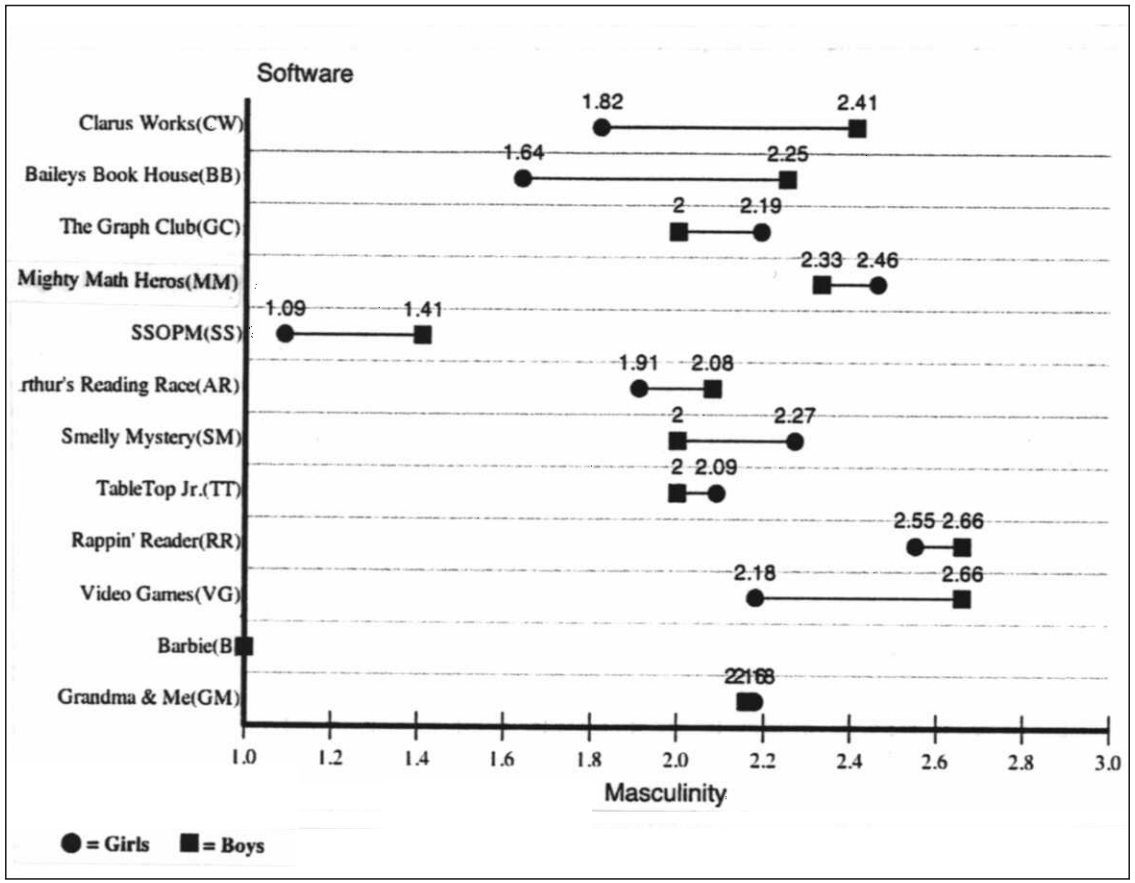

Figure 1. 2nd grade perceptions of software masculinity and femininity.

While the data show that, to some degree, girls and boys agree as to the masculinity/femininity of individual software programs. Where there is disagreement a closer analysis of their rankings show that, with the exception of Bailey's Book House, their disagreement centered on the degree of masculinity to attribute to a program. Girls and boys agreed that the software in dispute was more appealing to boys, but disagreed about whether it was somewhat also appealing to girls.

The teacher was surveyed to ascertain her perceptions as to whether the software program was designed for girls, boys or both. She viewed Barbie and Say, Say Oh Playmate as designed for girls, Rappin' Reader as designed for boys and the other programs as designed for both boys and girls. Perhaps the most important finding here is that students do often perceive individual software programs as targeted toward a specific gender group.

\section{Fourth Grade}

Fourth grade girls viewed three programs-Barbie, Say, Say Oh Playmate, and Neighborhood Map Machine as designed for girls, Storybook Weaver 
and Neighborhood Map Machine as designed for girls and designed for both, Mighty Math Number Heroes as more likely designed for boys and the remaining programs as designed for both girls and boys (see Figure 2). Fourth grade boys viewed Barbie and Say, Say Oh Playmate as designed for girls, Storybook Weaver as designed for girls and designed for both, Mighty Math Number Heroes and Video Games as designed for boys and the remaining programs as designed for both. Fourth grade girls and boys only differed significantly in regards to Neighborhood Map Machine $(p=.035)$ and Video Games $(p=.047)$.

\section{Relationship between Preferences and Perceived Software Masculinity and Femininity}

The above data has documented that there are gender differences in students' software preferences and that students perceive software along a masculinity and femininity continuum. The hypothesis raised throughout this article is that students' software preferences are related to software masculinity and femininity

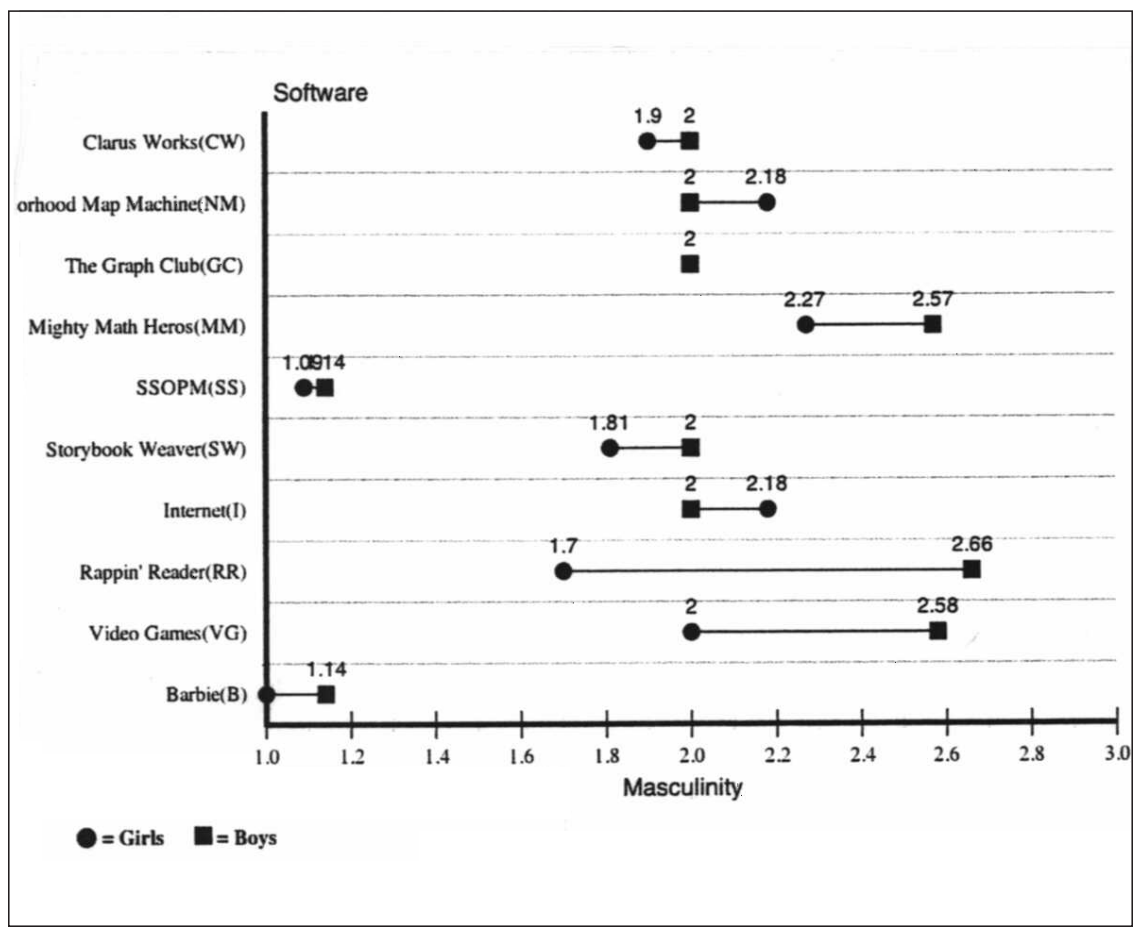

Figure 2. 4th grade perceptions of software masculinity and femininity. 
perceptions. To explore this relationship, students' software preferences and perceptions were compared.

\section{Second Grade}

The data represented in Figure 3 indicates girls' software preferences to be related to their perceptions of a software program's femininity. Boys' software preferences were related to their perceptions of a software programs' masculinity. According to the second grade girls' perceptions, three of their top five favorite programs (Barbie Software; Say, Say Oh Playmate; and Bailey's Book House) were viewed as designed for girls and two programs (Arthur's Reading Race and Video Games) were viewed as designed for both boys and girls. According to the second grade boys' perceptions, three out of five of their favorite programs (Smelly Mystery, Video Games, and Rappin' Reader) were viewed as designed for boys, one program (Mighty Math Number Heroes) was viewed as equally designed for boys and for both girls and boys and 1 program (Arthur's Reading Race) was viewed as designed equally for boys, girls, and both boys and girls.

\section{Fourth Grade}

The hypothesis that a high correlation exists between a student's preference for a program and the student's perception that the program was designed for their gender held true for fourth grade girls. Girls' first and third favorite programs (Barbie and Say, Say Oh Playmate) were clearly viewed by both girls and boys as having been designed for girls. Their second favorite program, Neighborhood Map Machine, was mostly perceived by girls as designed for girls and for both boys and girls. For the fourth grade boys, their first and third favorite programs (video games and Mighty Math Number Heroes) were viewed by boys as having been designed for them. They viewed Neighborhood Map Machine, their second favorite program, as one that was designed for either gender. Furthermore, fourth grade girls perceived that $78 \%$ of the programs they had experience with were designed for both boys and girls, $22 \%$ were designed for girls and none were designed primarily for boys. Fourth grade boys perceived that $44 \%$ of the programs they had experience with were designed for both boys and girls, $33 \%$ for boys and $22 \%$ for girls. Their teacher viewed $22 \%$ of the programs used in her classroom as having been designed for girls, $11 \%$ for boys and $67 \%$ for either.

The perceived masculinity/femininity of software programs was consistent between fourth grade boys and girls (see Figure 4). In general, girls liked many of the same programs as boys, but girls tended to view them as gender neutral, whereas boys viewed the same programs as having been designed for males. But it was very clear to the girls that their overall favorite program, Barbie Software, was designed with girls in mind. A possible interpretation of this finding is that girls believe that few games are specifically designed for them and that they really 


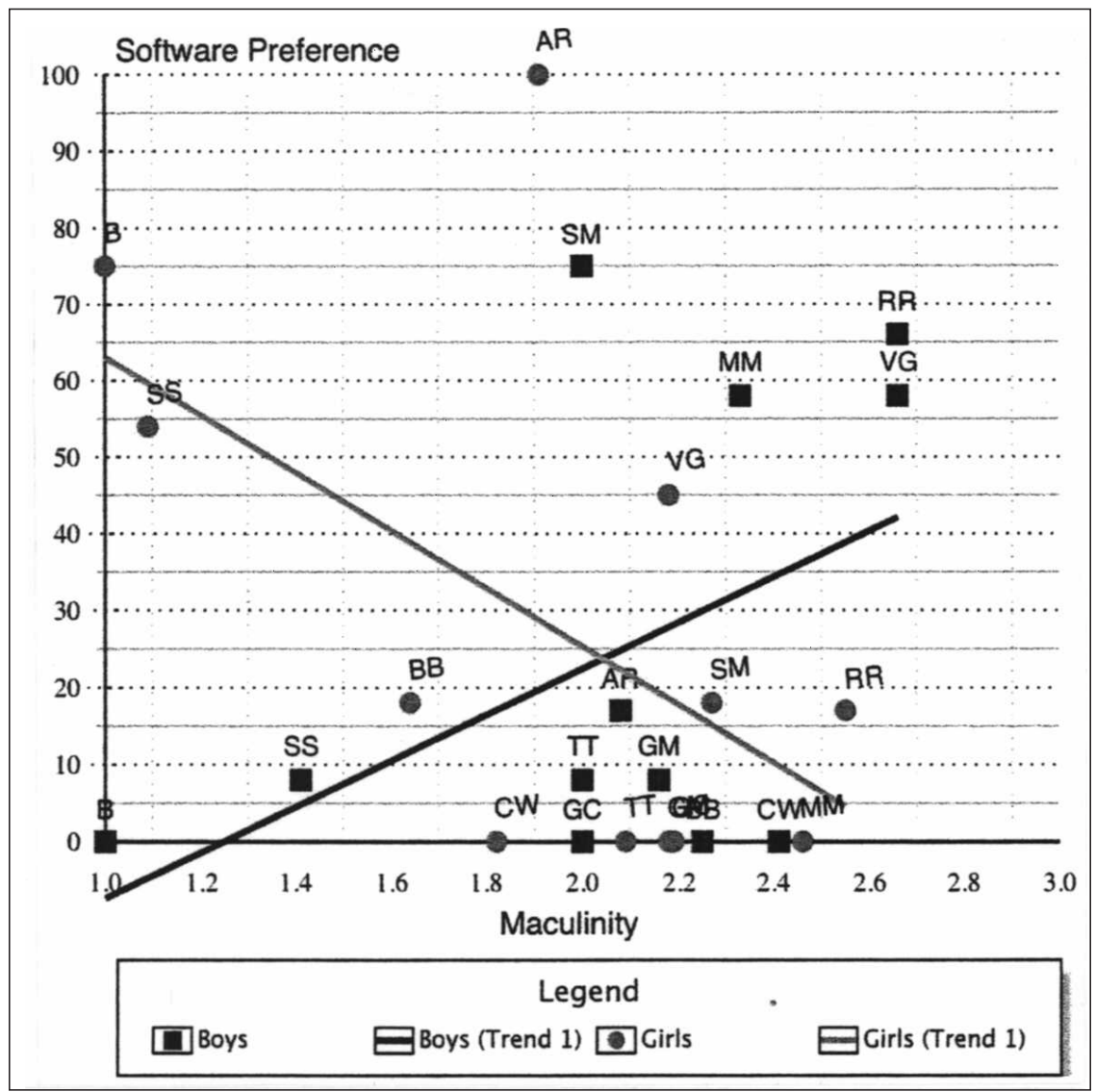

Figure 3. 2nd grade students software preferences and masculinity perceptions.

enjoy the ones that are. The data show that boys tend to believe that a larger number of programs are designed for boys.

\section{Discussion}

The data collected for this study show that even young students perceive some software programs as "gendered by design"-regardless of the designers' intentions and regardless of whether or not the students have access to computer technology at home. Furthermore, the data show that how students perceive a software program's masculinity and/or femininity is correlated with the likelihood that they will prefer the program. In other words, girls prefer software they perceive as less masculine - designed for girls - and boys prefer software they perceive as having been designed for boys. 


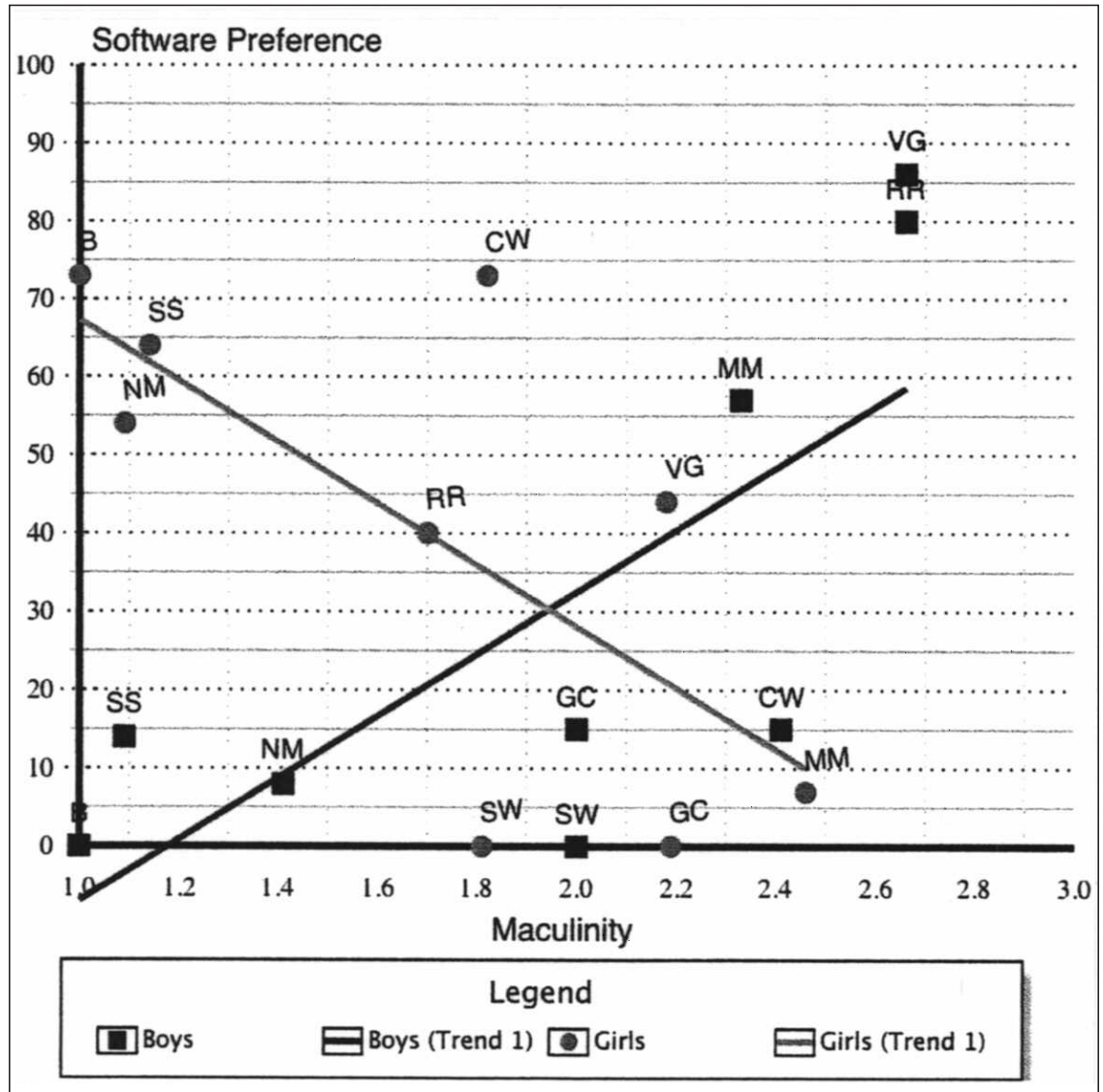

Figure 4. 4th grade students software preferences and masculinity perceptions.

In the introduction I argue that an overabundance of data on the preferences of mid and high SES students living in two-parent households with home access to computers might present a false picture of gender-based perceptions for all students, especially for low-income minority students who are more likely to come from single-parent families (mostly headed by females). I believe the results of this study support this hypothesis. These results, added to the existing research, show that gender differences exist for all students regardless of SES, ethnicity and/or family structure.

\section{Classroom Environment}

Important differences were observed in the ways computers were used in the two classrooms. Second grade students had more freedom of choice in terms of 
software selection and choice of computer partner. I believe that this environment was conducive to experimentation with different software programs and making clear choices as to which ones were the students' favorites. From in-class observations during the Say, Say Oh Playmate study, it was clear that students preferred same-sex partners for computer assignments and small-group projects. In addition, computer groups often purposely chose programs that other groups were not using, making it unusual for any two groups to be working with the same program at the same time.

The fourth grade teacher was more likely to tightly control her students' computer use-for example, requiring them to complete a specific assignment with pre-selected partners, usually in pairs or groups that contained a balance of boys and girls. When asked about her concern for balance, the teacher said that boys were less likely to complete their assignments if they worked in all-boy pairs or groups. The researchers believe that part of the reason why the fourth grade boys did not describe themselves as "good at computers" was the practice of using computer time as a reward. Good behavior allowed students to accumulate computer time. Girls built up large amounts of time, but discipline problems stopped boys from getting enough computer time to experiment with various software programs.

As reported above, fourth grade students were more likely to perceive software as being designed for both boys and girls, while second grade students were more likely to perceive software as being designed for either boys or girls. It is possible that the classroom environment also influenced these perceptions. Second grade students were allowed to self-select the software used during their time on the computer, while fourth grade students were almost always assigned work with a specific program. Second grade students were therefore given greater freedom to establish their own perceptions and preferences and were more likely to choose a gender-specific program.

\section{Video Games}

Researchers continue to report findings on the lack of computer technology in low-income minority homes. However, when citing computer use many studies overlook the fact that a large percentage of low-income minority households, especially those headed by African Americans, contain a video game player. In this study over $75 \%$ of the second and fourth grade students combined said that they had a video game player at home. While not the same as a computer, I believe these machines are capable of exerting a strong influence on a student's perception of technology before they start attending school. For all of the surveyed students, a strong relationship was noted between the amount of time spent playing Nintendo/Sega and self-confidence in using computers $(r=.309)$. More research is required to determine whether time spent playing video games actually has a causal effect on how students feel about their overall computer skills. 
One factor that is frequently suspected as negatively affecting girls' selfperceptions of their computer skills is the dominant use of home computers by males. Therefore I assume that, since many low-income families do not own a computer, children from those families may not begin their education with a gender biases regarding technology use. I believe that student use of video games at home can have a similar and possibly greater influence on students' perceptions of their ability due to the likelihood that students are more apt to spend more time playing video games than using computers, even when both are present in the home. In the present study, the results showed that fourth grade girls who had higher levels of self-confidence in their overall computer skills when compared with their male classmates were more likely to live in a household that had a computer or video game player.

\section{CONCLUSION}

I began this inquiry by challenging 1) the dominant assumption that social factors are the primary determinant of students' gendered perceptions of technology and 2) the limited diversity in terms of socioeconomic and ethnic backgrounds of students who are the focus of many studies in this area. Based on the survey responses my conclusion is that both social and design factors influence students' gendered perceptions of software and software preferences. For mid and high income students, computer access and parental usage patterns at home probably does exert a strong influence on students' perceptions of their computer skills. However, it is important to consider that cheaper technologies, such as video game players, may be equally influential on the self-perceptions of computer skills held by low-income minority students, many of whom live in households headed by single females.

There is much work left to be done on the complex influences of social and design factors on students' perceptions of and preferences for certain software programs. The sample I worked with was quite small, therefore more data is required to support or refute my hypothesis that student software preferences are closely related to their perceptions of which gender a program is designed for. One area for additional research is comparing the perceptions of students, designers and teachers about which gender software programs are targeting. The result from this study calls for an extension of the search for what initiates gender differences to include software designers' design decisions, teachers' instruction and perceptions as well as video games usage in the home. Understanding how different groups perceive software programs can lead to an understanding of how to impact each group's use of software. In order to improve the chances that all students' needs are being met—male, female, African American, Latino, Caucasian, Asian, and Native American - we need to look at how their particular experiences, interests, and knowledge can be incorporated into software design. The guiding question in such research and development should be whether a 
relationship exists between student learning and the perception that a particular piece of software was designed with the student's interests in mind.

\section{REFERENCES}

AAUW Educational Foundation (1998). Gender gaps: Where schools still fail our children. Researched by The American Institutes for Research. Washington, DC: American Association of University Women Educational Foundation.

AAUW Educational Foundation. (2000). Tech-Savvy: Educating Girls in the New Computer Age. Researched by Commission on Technology, Gender, and Teacher Education. Washington, DC: American Association of University Women Educational Foundation.

Becker, H. J., \& Sterling, C. W. (1987). Equity in school computer use: National data and neglected considerations. Journal of Educational Computing Research, 3(3), 289-311.

Bunderson, E. D., \& Christensen, M. E. (Fall, 1995). An analysis of retention problems for female students in university computer science programs. Journal of Research on Computing in Education, 28(1), 1-18.

Clewell, B. (2002). Breaking the barriers: The critical middle school years. In The JosseyBass reader on gender in education. San Francisco: Jossey-Bass.

Dyer, S. K. (Ed.). (2004). Under the microscope: A decade of gender equity projects in the sciences. Washington, DC: AAUW Educational Foundation.

Eastman, S. T. \& Krendl, K. (1987). Computers and gender: Differential effects of electronic search on students' achievement and attitudes. Journal of Research and Development in Education, 20(3), 41-48.

Fishman, B., \& Pinkard, N. (2001). Bringing urban schools into the information age: Planning for technology vs. technology planning. Journal of Educational Computing Research, 25(1), 63-80.

Furger, R. (1998). Does Jane compute? Preserving our daughters' place in the cyber revolution. New York: Warner.

Hawkins, J. (1987). Computers and girls: Rethinking the issues. In R. D. Pea \& K. Sheingold (Eds.), Mirror of minds: Patterns of experience in educational computing (pp. 242-257). Norwood, NJ: Ablex.

Hanor, J. H. (1998). Concepts and strategies learned from girls' interactions with computers. Theory into Practice.

Honey, M., Moeller, B., Brunner, C., Bennett, D., Clements, P., \& Hawkins, J. (1991). Girls and design: Exploring the question of technological imagination (CTE Technical Report Issue No. 17). New York: Center for Children and Technology, Bank Street College of Education.

Knupfer, N. N. (1998). Gender divisions across technology advertisements and the WWW: Implications for educational equity. Theory into Practice, 37, 54-63.

Lenhart, A. (2003). The ever-shifting Internet population: A new look at Internet access and the digital divide (pp. 1-46). Washington, DC: The PEW Internet American Life Project.

Lepper, M. R., \& Malone, T. (1987). Intrinsic motivation and instructional effectiveness in computer-based education. In R. Snow \& M. Farr (Eds.), Aptitude, learning and instruction: Conative and affective process analyses (pp. 255-286). Hillsdale, NJ: Lawrence Erlbaum Associates. 
Malone, T., \& Lepper, M. R. (1987). Making learning fun. In R. Snow \& M. Farr (Eds.), Aptitude, learning and instruction: Conative and effective process analyses (pp. 223-253). Hillsdale, NJ: Lawrence Erlbaum Associates.

McConnaughey, J. W. \& Lader, W. (1998). Falling through the net: New data on the digital divide. National Telecommunications and Information Administration.

Miller, L., Chaika, M., \& Groppe, L. (1996). Girls' Preferences in software design: Insights from a focus group. Interpersonal Computing and Technology: An Electronic Journal for the 21st Century, 4(2), 27-36.

Miura, I. (1987). Gender and socioeconomic status differences in middle-school computer interest and use. Journal of Early Adolescence, 7(2), 243-253.

Pinkard, N. (2000). Lyric reader: Architecture for creating intrinsically motivating and culturally relevant reading environments. Interactive Learning Environments.

Pinkard, N. (2001). Rappin' Reader and Say, Say Oh Playmate: An exploration of a culturally relevant beginning literacy computer-based learning environment. Journal of Educational Computing Research, 25(1).

Pinkard, N. (1999). Culturally responsive computer-based literacy environments. Center for the Improvement of Early Reading Achievement (Technical Report 1.004).

Pinkard, N. (2001). Leveraging background knowledge: Using popular music to build children's beginning reading skills. Unpublished doctoral dissertation. Evanston, IL: Northwestern University.

Purple Moon. (1995). Summary of national research: Process and results, how gender differences affect play behavior of girls and boys, ages 7-12. Available at http://www.purple-moon.com/cb/laslink/pm?stat+corp+research_highlights.

Schofield, J. W. (1995). Computers and classroom culture. New York: Cambridge.

Shashaani, L. (1994). Gender differences in computer experience and its influence on computer attitudes. Journal of Educational Computing Research, 11(4), 347-367.

Vail, K. (1997, June). Girlware: Software companies are targeting girls, but is their marketing on the mark? Electronic School Online, available at http://www.electronic-school.com/0697fl.html_.

\section{Direct reprint requests to:}

Dr. Nichole Pinkard

Center for Urban School Improvement

The University of Chicago

1313 E. 60th Street

Chicago, IL 60637

e-mail: pinkard@usi.uchicago.edu 